\title{
Chikungunya, Dengue, and Zika in Immunocompromised Hosts
}

\author{
Luiz Guilherme Darrigo Jr. ${ }^{1}$ Alexandre Machado de Sant'Anna Carvalho ${ }^{2}$ - Clarisse Martins Machado ${ }^{2,3}$
}

Published online: 17 March 2018

(C) The Author(s) 2018

\begin{abstract}
Purpose of Review Describe the characteristics of chikungunya, dengue, and Zika in transplant recipients and immunocompromised hosts.

Recent Findings Stem cell/bone marrow grafts, organs, and blood transfusions can transmit CHIKV/DENV/ZIKV infections, which are clinically similar, resembling influenza-like illness. Laboratory confirmation is necessary. In the acute phase, RT-PCR is preferred. DENV and ZIKV serology may cross-react. Delayed engraftment and extended viruria is observed in ZIKV+/HSCT recipients, while longer viremia is observed in DENV+/HSCT patients. Arbovirus persistence in organ tissues is generally unknown. Vaccine development is in early stages for CHIKV/ZIKV. No data is available to recommend the licensed DENV vaccine in transplant recipients.

Summary In endemic areas, the assessment of epidemiological risk is mandatory. Donor deferral for 120 days in suspected or confirmed ZIKV+ has been recommended, while CHIKV+ donors should wait 30 days. No deferral is recommended for DENV+ donors. CHIKV/DENV/ZIKV tests should be included in the differential of febrile neutropenia and other transplant syndromes. Reassessment of DENV serology is urgently needed. Prospective studies are necessary to determine the impact of CHIKV/ DENV/ZIKV in this special population.
\end{abstract}

Keywords Chikungunya $\cdot$ Zika $\cdot$ Dengue $\cdot$ Transplantation $\cdot$ Immunocompromised hosts $\cdot$ Arboviruses

\section{Introduction}

Diseases caused by arboviruses may represent a major threat to immunocompromised hosts living in or traveling to endemic regions. Although dengue is the most common mosquitoborne disease in tropical and subtropic regions, two new arboviral diseases, chikungunya and Zika, have been recently introduced in the Americas. These three arboviruses have

This article is part of the Topical Collection on Transplant and Oncology

Clarisse Martins Machado

clarimm@usp.br

1 Bone Marrow Transplant Unit - Ribeirão Preto Medical School, University of São Paulo, Ribeirão Preto, São Paulo, Brazil

2 Virology Laboratory - Institute of Tropical Medicine, University of São Paulo, Av. Dr. Enéas de Carvalho Aguiar, 470 - 2nd floor, São Paulo, SP 05403-000, Brazil

3 HSCT Program, Amaral Carvalho Foundation, Jahu, São Paulo, Brazil posed new challenges in the transplantation setting, such as lack of specific serological tests, possibility of blood and graft transmission, and restrictions in donor selection. The diseases have a similar clinical presentation in the acute phase, hindering appropriate diagnosis, case management, and sometimes prompting severe and fatal events.

In this review, relevant data on chikungunya, dengue, and Zika infections in transplant recipients and immunocompromised hosts is discussed.

\section{Dengue}

Dengue is a mosquito-borne viral disease that occurs both as an endemic or epidemic disease. Dengue virus (DENV) is a small single-stranded RNA virus comprising four main serotypes belonging to the genus Flavivirus, family Flaviviridae, and transmitted by mosquitoes of the genus Aedes (Aedes aegytpi and Aedes albopictus) [1]. Infection by one serotype provides lifelong immunity against that serotype, but only partial protection against subsequent infections by other 
serovars. In immunocompetent hosts, there is good evidence that secondary infection increases the risk of more serious disease due to antibody-dependent enhancement (ADE), resulting in dengue hemorrhagic fever (DHF) or dengue shock syndrome (DSS). Patients with severe dengue have elevated circulating levels of IL- 8 , IL-10, TGF- $\beta$, and interferon- $\gamma$ [2]. Therefore, a robust immunologic response is a prerequisite for the development of DHF or DSS.

\section{Epidemiology}

An estimated 3.9 billion people in 128 countries are at risk of infection with DENV [3]. A recent study indicates that around 390 million dengue infections occur every year, of which 96 million manifest clinically with variable severity [4]. In the last 15 years, dengue outbreaks have been reported in most World Health Organization (WHO) regions. In 2016, more than 2.38 million cases with 1032 deaths were reported in the Americas, where Brazil alone contributed with approximately 1.5 million cases [5].

In the last 5 years, an increasing number of dengue has been described in transplant recipients due to the expansion of DENV [1]. So far, more than 180 cases have been reported $[6 \bullet \bullet, 7,8,9 \bullet \bullet, 10,11]$. In endemic areas, this number may be much higher, since most cases are mild and present as a flulike illness, with some manifestations resembling posttransplant syndromes.

\section{Dengue Transmission in Transplantation}

More than $95 \%$ of the transplant recipients acquired dengue by vector transmission, as they were living or traveled to endemic areas $[6 \bullet \bullet, 10,11]$. Although mosquito bites are the most frequent mode of transmission, other sources of infection are relevant in the transplant setting, such as the graft itself and blood transfusions.

Graft transmission is rare but has been well documented in two cases of hematopoietic stem cell transplantation (HSCT) $[12 \bullet, 13]$. The first case occurred during the 1994-1995 dengue epidemic in Puerto Rico. The patient died 11 days after HSCT and DENV4 was detected in blood, ascitic fluid, and tissue samples. The donor developed fever 2 days after marrow harvesting and DENV4 serotype was confirmed in donor samples [12•]. The other case of graft transmission occurred in a HSCT recipient whose unrelated donor had returned from Sri Lanka 3 days before donation [13]. Graft transmission has also been reported in solid organ transplant (SOT) recipients [14]. A living donor who developed symptoms 2 days after donation transmitted dengue to a liver transplant recipient in Delhi [15•]. Transfusion-transmitted (TT) dengue has also been demonstrated. Viremic donors have been detected during outbreaks and most TT/DENV+ cases are asymptomatic
[16••, 17-19]. So far, routine NAT for dengue is not recommended in blood banks.

During dengue season in endemic areas, asymptomatic SOT/HSCT donors who live or have traveled to the region should be directed to report dengue symptoms appearing in the first week after donation. Donor deferral is currently not recommended.

\section{Clinical Manifestations}

Dengue has a wide clinical spectrum varying from asymptomatic to severe clinical manifestations. In the immunocompetent population, seroprevalence studies suggest that the number of asymptomatic carriers is threefold to that of dengue fever cases.

Symptomatic dengue is currently grouped into three categories: dengue without warning signs (DNWS), dengue with warning signs (DWWS), and severe dengue (SD), as shown in Fig. 1 [20•]. The absence of warning signs does not preclude the possibility of severe disease and lethal outcome [1].

After a 3- to 15-day incubation period, the disease presents abruptly as a flu-like illness in three phases, i.e., febrile, critical, and recovery. This stereotypical course is often altered in transplant patients, where longer duration of symptoms and thrombocytopenia occur in more than $80 \%$ of cases.

A recent study including five $\mathrm{HSCT} / \mathrm{DENV}+$ patients showed main clinical findings to be fever $(100 \%)$, myalgia $(80 \%)$, thrombocytopenia $(80 \%)$, and rash $(60 \%)$, with or without hemorrhagic episodes, similar to immunocompetent individuals. Severe DHF occurred in one patient (20\%). An important finding of this study was the observation of prolonged viremia (more than 15 days) in all patients who had blood samples collected serially [6••]. In the immunocompetent population, dengue viremia persists from 4 to 7 days (median 5 days) in $69 \%$ of the patients, being uncommon after the fifth day $(12.5 \%)$ [21, 22].

Among SOT recipients, the largest case series was published in 2013 and reported the clinical findings of 102 DENV cases after renal transplantation [9••]. Forty-four patients $(43 \%)$ had primary and $58(56.8 \%)$ had secondary dengue infection. Thrombocytopenia was seen in $95 \%$ of cases, with a mean duration of $11 \pm 9$ days. Most patients presented with fever $(80 \%)$, which was less frequent in patients receiving high-dose steroids. DF occurred in $88 \%$ and DHF/DSS occurred in $11.7 \%$, with graft dysfunction in $66.7 \%$ of these. Interestingly, patients on a cyclosporine (CSA)-containing regimen had less severe disease [9••]. Some authors have shown that CSA can be a potential drug for the treatment of flavivirus infections [23•].

In immunocompetent hosts, dengue mortality rates vary from $0.026 \%$ in DF up to $5 \%$ in DHF/DSS [24]. Studies in transplant populations show mortality rates ranging from 0 to $100 \%$ in case reports and 0 to $37.5 \%$ in case series. The main 
Fig. 1 Current classification of symptomatic Dengue infection [20•]

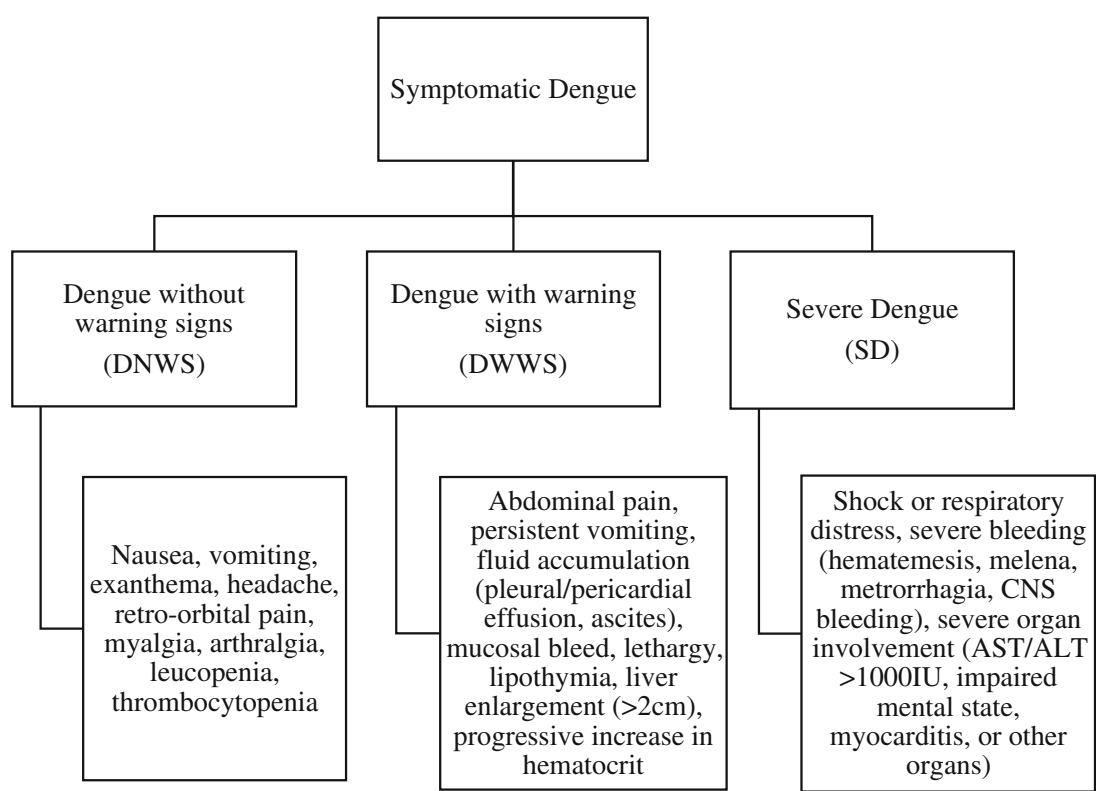

publications highlighting these findings have been recently summarized [6••]. Prospective studies may better determine the morbimortality of dengue in transplant cohorts as well as the variables associated with severe forms of the disease.

\section{Diagnosis}

After disease onset, the virus can be detected in serum, plasma, circulating blood cells, and other tissues for 4-5 days. Virus isolation, NS1 antigen detection that yields results within a few hours, or nucleic acid test (NAT) can be used to diagnose dengue in the acute phase. A recent study showed that prolonged viremia (over 15 days) is frequently observed in transplant patients, thus NAT can be used to diagnose dengue even after the first week of illness in this population [6••].

After the acute phase of infection, serology is the method of choice for diagnosis. Specific IgM antibodies are detectable in $50 \%$ of patients by days 3-5 after illness onset, increasing to $80 \%$ by day 5 and $99 \%$ by day 10 . IgM levels peak about 2 weeks after the onset of symptoms and then decline to undetectable levels over 2-3 months. IgG is detectable at low titers at the end of the first weeks, increasing slowly thereafter with serum IgG still detectable after several months, probably for life [1].

In recent years, with the spread of ZIKV and CHIKV in dengue regions, cross-reactivity in serological tests has unfortunately been observed, with some Zika patients testing as false-positives for dengue $[25,26 \bullet \bullet$. As a result, both diagnosis and seroprevalence estimates are compromised.

\section{Clinical Management}

Fever and exanthema are good markers of arbovirus infection, especially during mosquito season, and should prompt DENV,
ZIKV, and CHIKV investigation [27••]. Thrombocytopenia is a hallmark of dengue and helps to differentiate it from other

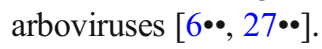

Overall assessment includes history, physical exam, laboratory tests, and evaluation of disease severity [11]. Based on the findings, clinicians are able to determine the phase of the disease, the presence of warning signs, and if the patient requires admission.

There is no specific antiviral drug to treat dengue. Generous fluid replacement is the mainstay of therapy. Seropositive patients have a risk of developing severe dengue in case of secondary DENV reinfection with different serotypes. However, this tendency has not been confirmed in transplant recipients. The $\mathrm{T}$ cell immunosuppression induced in this population and consequent low inflammatory response may explain these findings. Currently, there is no evidence to recommend decreasing immunosuppression in transplanted patients, as it does not seem to affect the outcome and may trigger graft rejection $[9 \bullet \bullet]$.

\section{Chikungunya}

Chikungunya virus is an arbovirus, belonging to the family Togaviridae genus Alphavirus. It is transmitted by Aedes mosquitoes (Aedes albopictus and Ae. aegypti) and was first isolated in the 1952 outbreak in a southern province of Tanzania [28, 29]. After limited outbreaks in Asia in the 50 s and 60s, the disease re-emerged in the early 2000s and rapidly spread throughout Africa and Europe [30]. Until now, four lineages distinguished by genotypes have been identified [31]. 


\section{Epidemiology}

During the 2004 epidemic, which began in Africa, several outbreaks were reported in the Indian Ocean islands. Afterwards, an outbreak occurred in La Reunion Island, affecting approximately $34 \%$ of the population. In 2006, several cases of CHIKV infection were reported in Europe [32, 33]. In 2013, cases of CHIKV infection were reported in St Martin Island and spread throughout the Caribbean, Central America, and South America [34]. In 2014, cases of CHIKV began to be identified among returning travelers from the USA who visited affected areas. Local transmission was identified in Florida, Puerto Rico, and the US Virgin Islands. In the same year, the first case of autochthonous CHIKV was identified in Brazil [35]. Between 2015 and 2017, more than 300,000 cases were notified to the Brazilian episurveillance system, with $40 \%$ of municipalities confirming cases [33, 35]. Currently, Brazil accounts for more than $90 \%$ of confirmed cases in the Americas [36].

\section{Chikungunya Transmission in Transplantation}

Besides vector transmission, few articles discuss CHIKV transmitted by organ transplantation or blood transfusion. In the 2005 outbreak in La Réunion, CHIKV was detected in 4 of 12 healthy donors of corneal grafts, demonstrating the potential risk of transmission during tissue transplantation [37•]. Previous reports of CHIKV transmission by blood donation estimated that the mean and maximal risks of viremic donations were 38 to 52 per 100,000 donations $(0.04$ to $0.06 \%)$, respectively [38].

The recommendations concerning donor screening for CHIKV are controversial. Couderc and colleagues observed silent eye infection in $33 \%$ of corneal donors during the outbreak in La Reunion and demonstrated that systemic infection followed cornea infection in animal model. The authors recommend that in the absence of systematic CHIKV screening in donors, cornea donation should be banned during CHIKV outbreaks [37॰]. There are no studies investigating long-term persistence of the virus in tissues, and the cost-effectiveness and clinical impact of such guidelines is subject to debate.

As the maximum viremic period of CHIKV infection is 2 days before and 17 days after symptoms [38], we suggest donor deferral for at least 30 days if SOT/HSCT donor lives or has traveled to endemic areas and presents with CHIKV symptoms or laboratory confirmation. We also recommend discussing the risk of donor-derived infection, especially in epidemic settings, and obtaining informed consent. Asymptomatic SOT/HSCT donors should be directed to report CHIKV symptoms appearing in the first week after donation.

\section{Clinical Manifestations}

After a mosquito bite, CHIKV reaches the bloodstream and spreads through the liver, muscles, joints, spleen, lymph nodes, and brain. In immunocompetent patients, the incubation period varies between 2 and 10 days [33]. After this, an abrupt onset of fever is observed, followed by malaise, maculopapular rash, myalgia, nausea, and headache. Persistent or recurring arthralgia is characteristic and helps to differentiate CHIKV from other arboviruses $[29,39 \bullet \cdot]$. A considerable number of patients develop chronic polyarthritis that persists for months or years after the acute phase. It is estimated that after 1 year, more than $20 \%$ of patients still have incapacitating joint pain [40]. Despite being a benign and self-limited disease, there are reports of neurologic and hepatic manifestations with fatal outcomes [41]. The fatality ratio is about 1 per 1000 , with most cases occurring among newborns and elderly [29].

Unlike ZIKV and DENV, CHIKV is symptomatic in more than $95 \%$ of cases [29]. However, in SOT recipients, the intensity of joint symptoms may not be as expressive as in immunocompetent individuals. Kee and colleagues reported two cases of CHIKV in a chronic kidney disease patient and liver transplant recipient associated with peritonitis, encephalitis, and secondary bacterial infections, but without arthralgia, which is characteristic of CHIKV infection [42].

In SOT, Chikungunya has been reported as a mild disease with favorable outcomes [43, 44]. The largest study of SOT/ CHIKV+ patients was performed in Ceará, an endemic area in the north of Brazil, where authors described 13 cases of CHIKV infection (9 kidney and 4 liver recipients) between January and December 2016. All patients had arthralgia and $84.6 \%$ had fever [45*0]. All individuals achieved full recovery without complications $[43-44,45 \bullet \cdot, 46 \bullet \cdot$. Similarly, $\mathrm{HSCT} / \mathrm{CHIKV}+$ patients have been reported without increased morbidity $[27 \bullet \bullet]$. The use of immunosuppressive drugs may play a role in the paucity of symptoms.

\section{Diagnosis}

CHIKV infection is diagnosed on the basis of clinical, epidemiological, and laboratory criteria. Lymphopenia is a key finding, although thrombocytopenia, increased AST/ALT and hypocalcemia may also be present [30]. The laboratory diagnosis is based on NAT in blood samples by reversetranscriptase PCR (RT-PCR), viral culture, or detection of IgM and IgG antibodies through serological tests. Viral isolation from blood cells is the gold standard but is rarely performed due to technical difficulty $[33,39,46 \bullet \cdot]$. In the first week of symptoms, RT-PCR is the method of choice. In transplant recipients, CHIKV viremia seems to be shorter than in DENV infection [27••].

\section{Clinical Management}

Treatment of acute CHIKV is mainly supportive [33]. Antiviral agents and monoclonal antibodies are in initial stages of testing. Wang and colleagues describe potential 
active compounds for treatment of CHIKV, such as Niclosamide and Nitazoxanide. Another compound, Suramin, has been shown to have anti-CHIKV action. Although promising, these results need to be confirmed in clinical trials [47]. An excellent review of potential therapeutic compounds was recently published [39••].

\section{Zika}

Zika virus is a Flavivirus, in the family Flaviviridae [48 • ]. In urban environments, two species are considered the main competent vectors, Aedes aegypti and less commonly, A. albopictus, which has a wider distribution in North America [48••]. ZIKV was first identified in 1947 in a sentinel rhesus monkey in the Zika Forest of Uganda. The first cases of human infection were published in Eastern Nigeria in 1952 [49]. Since then, few cases had been published until 2007 when an outbreak occurred in the island of Yap, Micronesia, with approximately 5000 cases reported, followed by outbreaks in the French Polynesia and Gabon [50, 51]. The virus was then confirmed in Brazil in May 2015 and in a few months more than 1.5 million cases were reported $[52,53]$. Following this rapid expansion through the Americas and the discovery of devastating effects of ZIKV during pregnancy, the World Health Organization (WHO) classified the epidemic as a public health emergency of international concern [54].

\section{Epidemiology}

From May 2015 to December 2016, as much as 707,133 cases of ZIKV in the Americas were reported, with the majority coming from South America, particularly Brazil [55]. Epidemiologists believe that the introduction of ZIKV in the country was facilitated by several international sports events hosted by Brazil, such as the Confederations Cup in 2013, the 2014 FIFA World Cup, among others [56, 57]. In their wake, reports of ZIKV were documented in the USA and Europe. At the end of 2015, a ZIKV outbreak in Cape Verde marked the return of the virus to Africa [58]. Recent data from WHO shows that around 75 countries have reported mosquitoborne ZIKV transmission [54].

\section{Zika Transmission in Transplantation}

The majority of ZIKV cases in transplant or immunocompromised patients were vector-borne. In SOT recipients, Nogueira and colleagues reported a series of four recipients (liver, 2; kidney, 2) who developed symptomatic ZIKV infection diagnosed by RT-PCR. All recovered without sequela [59 • ]. A case of ZIKV meningoencephalitis in a heart transplant recipient has also been reported [60॰]. A recent prospective study in HSCT/ZIKV+ patients in Brazil described clinical findings and outcomes on four cases during the ZIKV epidemic in Brazil [27••].

Alternative ways of transmission include sexual, perinatal, and via blood products. Transmission by transplantation is another possibility. Simkins and colleagues in Florida observed that $3 \%$ of the deceased donors had positive ZIKV IgG, and none had a positive ZIKV IGM or PCR [61]. During the French Polynesian ZIKV outbreak, Musso and colleagues reported incidence of $2.8 \%$ of blood donors ZIKV+ by PCR at time of donation [62••]. Puerto Rico and Brazil had 0.5 to $1 \%$ of donors found to be ZIKV RNApositive $[63,64]$. The first case of Zika in a liver transplant recipient was reported in Brazil and was transmitted by the platelet component transfused during surgery. The blood donor was asymptomatic at the time of donation. Data has shown that $80 \%$ of infections are asymptomatic $[62 \bullet \cdot 65 \cdot]$. Recently, transmission by platelet transfusion has been documented in two other patients [66].

Regarding deferral, US guidelines recommend that organ procurement organizations should focus on epidemiological risk factors, as well as donor symptoms, and highlight this information when organ offers are made [67]. This protocol suggests that concern for Zika should not summarily exclude donors from transplantation. Rather, the risk of donor derived infection should be balanced with the benefits of the procedure in each potential recipient. In the case of potential living donors with Zika infection, donation should be deferred where possible.

Other guidelines and most published studies suggest donor deferral for 120 days after suspected ZIKV resolution. Based on this data, many experts recommend that SOT/HSCT donors with ZIKV-positive workup, suggestive clinical presentation or travel, and unprotected sexual activity with partner affected by the virus to defer donation for 4 months [54].

\section{Clinical Manifestations}

The most common symptoms in ZIKV infection are maculopapular rash, mild fever, arthralgia, nonpurulent conjunctivitis, myalgia, headache, retro-orbital pain and, less commonly, vomiting, and edema [48••].

Unfortunately, ZIKV infection has been associated with severe congenital complications. Microcephaly is the most devastating feature of congenital infection in infants born to mothers affected by ZIKV during early pregnancy [68••]. In these patients, ocular abnormalities like pigment mottling, chorioretinal, and optic nerve atrophy were found in approximately $35 \%$ of cases [69]. Another complication is GuillainBarre syndrome (GBS), an acute self-limited peripheral neuropathy $[70,71]$. Other neurological disorders include acute myelitis and meningoencephalitis $[48 \cdot \bullet, 60]$. Some authors suggest that the neurological disorder present in ZIKV-induced GBS can be explained by direct neural injury caused by the virus or by a rapid cellular-mediated response to Zika [71-73]. 
In the transplantation setting, a report by Nogueira and colleagues describes four SOT/ZIKV+ patients that had concomitant bacterial infections requiring hospitalization. Complications such as graft dysfunction and arterial thrombosis were also observed, but all patients achieved full recovery [59・•]. In 2017, a case of ZIKV meningoencephalitis in a heart transplant recipient had a fatal outcome. However, the cause of death was acute cardiac allograft rejection, as a consequence of the abrupt interruption of immunosuppressive drugs due to ZIKV infection [60•].

In oncology and HSCT recipients, Machado and colleagues described a total of four cases of ZIKV. Prolonged viruria and delayed engraftment (HSCT) were observed in ZIKV patients with no further complications [27••]. No ZIKV infection has been reported in the European Society for Blood and Marrow Transplantation registry as of 05/15/2017 [74].

As the symptoms of ZIKV, CHIKV, and DENV are similar, these infections should be considered in the differential of neutropenic fever or rash in post-transplant settings, alongside cytomegalovirus, GVHD, and graft rejection $[47,75]$.

\section{Diagnosis}

Laboratory confirmation of ZIKV infection can be made through NAT and serology [76]. The definitive diagnosis is established by detection of viral nucleic acid in serum; however, most patients are asymptomatic and exhibit transient viremia ( 7 to 10 days) making diagnosis elusive. Recent studies have shown that ZIKV RNA persists significantly longer in whole blood than in plasma [77•]. Similarly, Gourinat and colleagues demonstrated that urine samples have higher viral loads for a longer time ( $>10$ days) when compared to serum. These findings could extend the window during which a definitive diagnosis of ZIKV can be established [78]. Another study compared serum and saliva samples indicating higher sensitivity of the saliva test compared to serum [79].

\section{Clinical Management}

So far, there is no specific therapy for ZIKV infection. Treatment for uncomplicated disease includes rest, hydration, and symptomatic management for fever and arthritis.

The main studies of Zika and chikungunya infections in transplant recipients are shown in Table 1.

\section{Preventive Measures}

Dengue, Zika, and chikungunya prevention is based on vector control and community-based programs to keep the environment free of potential breeding sources (discarded tires, flower vases, uncovered water storage barrels, etc). The mosquitoes breed in standing water $[53,80]$. In endemic regions, transplant patients should receive information about arbovirus transmission and Aedes habits to avoid exposure. Insect bites should be minimized by protective clothing and application of mosquito repellent ( $\mathrm{N}, \mathrm{N}$-diethyl-m-toluamide DEET, Picaridin or IR3535). Transplant recipients from non-endemic areas should avoid traveling to endemic areas [29, 31].

As of August 2017, there was one licensed vaccine against dengue and six in development: two in phase III, one in phase II, and three in phase I trials [81]. The licensed Sanofi-Pasteur

Table 1 Main studies of Zika and chikungunya infections in transplant recipients

\begin{tabular}{|c|c|c|c|c|c|}
\hline Author & Country & $\begin{array}{l}\text { Number of } \\
\text { patients }\end{array}$ & Virus & Population & Comments \\
\hline Courderc et al. $2012[37 \bullet]$ & France & 4 & CHIKV & Corneal grafts & $\begin{array}{l}\text { One third of uninfected corneal donors ( } 4 \text { of } \\
\text { 12) were infected with CHIKV during the } \\
\text { study period. }\end{array}$ \\
\hline $\begin{array}{l}\text { Dalla-Gasperina } \\
\quad \text { et al. } 2015 \text { [43] }\end{array}$ & Italy & 1 & CHIKV & Kidney transplant & $\begin{array}{l}\text { First case of CHIKV infection in an } \\
\text { HIV-infected kidney transplant recipient. }\end{array}$ \\
\hline Pierrotti et al. 2017 [44] & Brazil & 4 & CHIKV & Kidney transplant & $\begin{array}{l}\text { Described four cases of CHIK among } \\
\text { kidney transplant recipients. } \\
\text { Immunosuppression may have } \\
\text { ameliorated the symptoms }\end{array}$ \\
\hline Girão et al. 2017 [45••] & Brazil & 13 & CHIKV & $\begin{array}{l}\text { Kidney and liver } \\
\text { transplant }\end{array}$ & $\begin{array}{l}\text { SOT with CHIKV infection appears to have } \\
\text { an evolution similar to those seen in the } \\
\text { general population. }\end{array}$ \\
\hline Machado et al. 2017 [27••] & Brazil & 6 & ZIKV (4) CHKV(2) & HSCT & $\begin{array}{l}\text { Prolonged viruria in ZIKV cases. Delayed } \\
\text { engraftment in one patient who acquired } \\
\text { ZIKV } 25 \text { days before HSCT. }\end{array}$ \\
\hline Nogueira et al. 2017 [59••] & Brazil & 4 & ZIKV & $\begin{array}{l}\text { Kidney and liver } \\
\text { transplant }\end{array}$ & $\begin{array}{l}\text { Discusses the potential risk of bacterial } \\
\text { superinfection in immunocompromised } \\
\text { population with ZIKV infection. }\end{array}$ \\
\hline
\end{tabular}


DENV vaccine is a recombinant, chimeric live-attenuated tetravalent vaccine, to be administered in a 3-dose schedule at 6month intervals. The vaccine has been licensed for individuals aged 9-45 years living in areas with dengue seroprevalence $>$ $70 \%$. There is a clear benefit to people previously seropositive for DENV, with efficacy at 81.9\% CI95 (67.2-90.0) [82]. However, seronegative patients show efficacy of $52.5 \%$ CI95 $(5.9-76.1 \%)$ and increased attributable risk of 5 admissions and 2 severe cases per 1000 vaccinated in 5-year follow-up [81, 82]. The ADE phenomena may explain this observation. In seronegative patients, the vaccine mimics a silent primary infection that provides partially neutralizing antibodies for all serotypes. If the subject later acquires a natural, secondary dengue infection, the disease may exhibit a severe course [81]. According to the $\mathrm{WHO}$, this is the main obstacle to the widespread use of the licensed vaccine, and several questions must be answered before dengue vaccines are introduced broadly [83••].

The other dengue vaccine undergoing phase III clinical trials is the Butantan-DV vaccine, a live-attenuated tetravalent vaccine produced by the NIH and Butantan Institute. The results of a safety and efficacy trial (ClinicalTrials.gov identifier NCT01696422) in a DENV seropositive patient showed a robust expansion ( $\sim 70$-fold) of the plasmablast population post-vaccination, generating neutralizing titers for all serotypes by 91 days and amnestic response to DENV3 [84].

Until data becomes available from forthcoming studies, there is no recommendation concerning the use of dengue vaccines in immunocompromised individuals. Similarly, at this time, there is no recommendation for vaccination of travelers or health-care workers [83••].

Vaccines against Zika and chikungunya are still in early development and need to be tested for efficacy. ZIKV vaccination studies have been conducted in animal models, but no commercial vaccine is currently available [29, 85].

\section{Conclusions}

Clinical manifestations of CHIKV, DENV, and ZIKV infections are similar in transplant recipients. Some findings such as thrombocytopenia and arthralgia are more frequent in dengue and chikungunya, respectively, but do not ensure diagnosis. Fever, rash, nausea, vomiting, leucopenia, thrombocytopenia, and transient alterations of liver or renal functions are common findings in this population. Thus, epidemiological risk and laboratory workup is mandatory to diagnose arboviruses in transplant recipients living in or returning from endemic areas.

Serological diagnosis is currently a challenge, as recent data showed cross-reactivity of dengue tests in patients with proven ZIKV. The specificity of current dengue tests should be urgently reassessed. In addition, due to the high frequency of asymptomatic cases, DENV, CHIKV, and ZIKV may represent a threat to transplant recipients, as they can also be transmitted by blood transfusions or organ/tissue transplantation. So far, NAT is preferred in blood bank and pre-transplant donor selection, as well as in symptomatic or suspect cases after transplantation [86, 87]. Further research is needed to define the blood component to be tested (plasma, serum, whole blood) to ensure safety.

The burden of these diseases is unknown in the transplant setting, as only one prospective study has been conducted in symptomatic patients. Among the three discussed arbovirus infections, DENV showed greater morbidity with a protracted course, prolonged viremia and more complications.

No specific treatment is currently available and vaccines are in development. Management of arboviruses is mainly supportive, with attention to warning signs of decompensation.

Reduction of immunosuppression is not recommended as it may trigger rejection or GVHD. Preventive measures include vector control, avoidance of mosquito bites, and hopefully soon, vaccination.

The immunological consequences of DENV, CHIKV, and ZIKV persistence in blood and tissues, as well as its impact on the graft, need further investigation.

The neglected status of these diseases and lack of appropriate research funding poses a significant challenge for better understanding the many knowledge gaps in the field. Arboviruses are not contained by man-made borders. More research is urgently needed to elucidate the morbimortality of arbovirus in transplant cohorts including the variables associated with severe forms of the diseases.

\section{Compliance with Ethical Standards}

Conflict of Interest The authors have nothing to disclose.

Human and Animal Rights and Informed Consent This article does not contain any studies with human or animal subjects performed by any of the authors.

Open Access This article is distributed under the terms of the Creative Commons Attribution 4.0 International License (http:// creativecommons.org/licenses/by/4.0/), which permits unrestricted use, distribution, and reproduction in any medium, provided you give appropriate credit to the original author(s) and the source, provide a link to the Creative Commons license, and indicate if changes were made.

\section{References}

Papers of particular interest, published recently, have been highlighted as:

- Of importance,

-• Of major importance

1. World Health Organization. Dengue: guidelines for diagnosis, treatment, prevention and control: new edition. WHO Guidel Approv by Guidel Rev Committee. 2009. 
2. Pandey N, Jain A, Garg RK, Kumar R, Agrawal OP, Lakshmana Rao PV. Serum levels of IL-8, IFNgamma, IL-10, and TGF beta and their gene expression levels in severe and non-severe cases of dengue virus infection. Arch Virol. 2015;160(6):1463-75.

3. Brady OJ, Gething PW, Bhatt S, Messina JP, Brownstein JS, Hoen $\mathrm{AG}$, et al. Refining the global spatial limits of dengue virus transmission by evidence-based consensus. Reithinger R, editor. PLoS Negl Trop Dis. 2012;6(8):e1760.

4. Bhatt S, Gething PW, Brady OJ, Messina JP, Farlow AW, Moyes $\mathrm{CL}$, et al. The global distribution and burden of dengue. Nature. 2013;496(7446):504-7.

5. WHO PAHO. Dengue cases in the Americas. Vol. 2017, WHO PAHO. 2017. p. 1-3. Available from: http://www.who.int/mediacentre/ factsheets/2017-cha-dengue-cases-mar-27-ew-11.pdf?ua=1.

6.• de Souza Pereira BB, Darrigo Junior LG, de Mello Costa TC, Felix AC, Simoes BP, Stracieri AB, et al. Prolonged viremia in dengue virus infection in hematopoietic stem cell transplant recipients and patients with hematological malignancies. Transpl Infect Dis. 2017;19(4):e12721. Article showing prolonged viremia in dengue cases with blood samples taken prospectively, and awares the consequences on graft function.

7. Weerakkody R, Palangasinghe D, Dalpatadu KP, Rankothkumbura J, Cassim MR, Karunanayake P. Dengue fever in a livertransplanted patient: a case report. J Med Case Rep. 2014;8(1):378.

8. Fernandes PFCBC, Siqueira RA, Girão ES, Siqueira RA, Mota MU, Marques LCBF, et al. Dengue in renal transplant recipients: clinical course and impact on renal function. World J Transplant. 2017;7(1):57-63.

9.• Nasim A, Anis S, Baqi S, Akhtar SF, Baig-Ansari N. Clinical presentation and outcome of dengue viral infection in live-related renal transplant recipients in Karachi, Pakistan. Transpl Infect Dis. 2013;15(5):516-25. Largest series of DENV in renal transplant recipients, showing transient graft disfunction and liver enzymes alterations.

10. Machado CM. Transplant infections in developing countries. In: Ljungman P, Snydman D, Boeckh M, editors. Transplant infections. 4th ed. 2016. p. 129-50.

11. Weerakkody RM, Patrick JA, Sheriff MHR. Dengue fever in renal transplant patients: a systematic review of literature. BMC Nephrol. 2017;18(1):15.

12. Rigau-Pérez JG, Vorndam AV, Clark GG. The dengue and dengue hemorrhagic fever epidemic in Puerto Rico, 1994-1995. Am J Trop Med Hyg. 2001;64(1-2):67-74. First case of Dengue transmission by the graft in HSCT recipient.

13. Punzel M, Korukluoğlu G, Caglayik DY, Menemenlioglu D, Bozdag SC, Tekgündüz E, et al. Dengue virus transmission by blood stem cell donor after travel to Sri Lanka; Germany, 2013. Emerg Infect Dis. 2014;20(8):1366-9.

14. Tan FL-S, Loh DLSK, Prabhakaran K. Dengue haemorrhagic fever after living donor renal transplantation. Nephrol Dial Transplant. 2005;20:447-8.

15. Gupta RK, Gupta G, Chorasiya VK, Bag P, Shandil R, Bhatia V, et al. Dengue virus transmission from living donor to recipient in liver transplantation: a case report. J Clin Exp Hepatol. 2016;6(1): 59-61. First case of Dengue transmission by the graft in SOT recipient.

16.• Busch MP, Linnen JM, Vinelli E, Sabino EC, Tobler LH, Hyland C, et al. Dengue viremia in blood donors from Honduras, Brazil, and Australia. Transfusion. 2008;48(7):1355-62. First evidence of possible blood transmission of dengue.

17. Dias LL, Amarilla AA, Poloni TR, Covas DT, Aquino VH, Figueiredo LTM. Detection of dengue virus in sera of Brazilian blood donors. Transfusion. 2012;52(8):1667-71.

18. Levi JE, Nishiya A, Félix AC, Salles NA, Sampaio LR, Hangai F, et al. Real-time symptomatic case of transfusion-transmitted dengue. Transfusion. 2015;55(5):961-4.
19. Sabino EC, Loureiro P, Esther Lopes M, Capuani L, McClure C, Chowdhury D, et al. Transfusion-transmitted dengue and associated clinical symptoms during the 2012 epidemic in Brazil. J Infect Dis. 2016;212(11):694-702.

20. Alfaro A, Guzman MG, Martinez E, Pizarro D, Pleites E, Gutierrez $\mathrm{FH}$, et al. Dengue: guidelines for patient care in the region of the Americas. 2nd ed. Pan American Health Organization (PAHO), World Health Organization (WHO), editors. Washington, DC; 2016. 136 p. New clinical classification of Dengue.

21. Petersen LR, Tomashek KM, Biggerstaff BJ. Estimated prevalence of dengue viremia in Puerto Rican blood donations, 1995 through 2010. Transfusion. 2012;52(8):1647-51.

22. Guilardea O, Turchi MD, Siqueira JB Jr, Feres VC, Rocha B, Levi JE, et al. Dengue and dengue hemorrhagic fever among adults: clinical outcomes related to viremia, serotypes, and antibody response. J Infect Dis. 2008;197(6):817-24.

23. Qing M, Yang F, Zhang B, Zou G, Robida JM, Yuan Z, et al. Cyclosporine inhibits flavivirus replication through blocking the interaction between host cyclophilins and viral NS5 protein. Antimicrob Agents Chemother. 2009;53(8):3226-35. Possible therapeutic effect of cyclosporine on DENV.

24. Cox J, Mota J, Sukupolvi-Petty S, Diamond MS, Rico-Hesse R. Mosquito bite delivery of dengue virus enhances immunogenicity and pathogenesis in humanized mice. J Virol. 2012;86(14):7637-49.

25. Keasey SL, Pugh CL, Jensen SMR, Smith JL, Hontz RD, Durbin AP, et al. Antibody responses to Zika virus infections in environments of Flavivirus endemicity. Clin Vaccine Immunol. 2017;24(4):1-16.

26.• Felix AC, Souza NCS, Figueiredo WM, Costa AA, Inenami M, da Silva RMG, et al. Cross reactivity of commercial anti-dengue immunoassays in patients with acute Zika virus infection. J Med Virol. 2017;89(8):1477-9. This article shows the cross-reactivity of commercial kits of dengue serology in serum from patients with acute ZIKV infection.

27.• Machado CM, Pereira BBS, Felix AC, Oliveira MC, Darrigo LG, de Souza MP, et al. Zika and chikungunya virus infections in hematopoietic stem cell transplant recipients and oncohematological patients. Blood Adv. 2017;1(10):624-7. First prospective study of arbovirus in hematopoietic stem cell transplant recipients and oncohematological patients. Highlights the protracted and more severe course of Dengue and prolonged viremia.

28. Robinson MC. An epidemic of virus disease in Southern Province, Tanganyika territory, in 1952-53. I. Clinical features. Trans R Soc Trop Med Hyg. 1955;49(1):28-32.

29. Morens DM, Fauci AS. Chikungunya at the Door-Déjà Vu All Over Again? N Engl J Med. 2014;371(10):885-7.

30. Weaver SC, Lecuit M. Chikungunya virus and the global spread of a mosquito-borne disease. N Engl J Med. 2015;372(13):1231-9.

31. Mathew AJ, Ganapati A, Kabeerdoss J, Nair A, Gupta N, Chebbi P, et al. Chikungunya infection: a global public health menace. Curr Allergy Asthma Rep. 2017;17(2):1-9.

32. Powers $\mathrm{AM}$, Logue $\mathrm{CH}$. Changing patterns of chikungunya virus: re-emergence of a zoonotic arbovirus. J Gen Virol. 2007;88(Pt 9): 2363-77.

33. da Cunha RV, Trinta KS. Chikungunya virus: clinical aspects and treatment - a review. Mem Inst Oswaldo Cruz. 2017;112(8):523-31.

34. Nhan TX, Claverie A, Roche C, Teissier A, Colleuil M, Baudet JM, et al. Chikungunya virus imported into French Polynesia, 2014. Emerg Infect Dis. 2014;20(10):1773-4.

35. Faria NR, Lourenço J, Marques de Cerqueira E, Maia de Lima M, Carlos Junior Alcantara L. Epidemiology of chikungunya virus in Bahia, Brazil, 2014-2015. PLOS Currents Outbreaks. 2016 Feb 1. Edition 1.

36. Collucci C. Brazil sees sharp rise in chikungunya cases. BMJ. 2016;354(i4560):4560.

37. Couderc T, Gangneux N, Chrétien F, Caro V, Le Luong T, Ducloux $\mathrm{B}$, et al. Chikungunya virus infection of corneal grafts. J Infect Dis. 
2012;206(6):851-9. First publication of possible transmission of CHIKV by corneal grafts during epidemics.

38. Appassakij H, Promwong C, Rujirojindakul P, Wutthanarungsan R, Silpapojakul K. The risk of blood transfusion-associated chikungunya fever during the 2009 epidemic in Songkhla Province. Thail Transfus. 2014;54(8):1945-52.

39.• Abdelnabi R, Neyts J, Delang L. Chikungunya virus infections: time to act, time to treat. Curr Opin Virol. 2017;24:25-30. This study documented some of the recently small molecule inhibitors of CHIKV replication.

40. Mccarthy MK, Morrison TE. Chronic chikungunya virus musculoskeletal disease: what are the underlying mechanisms ? Future Microbiol. 2016;11:331-4.

41. Lemant J, Boisson V, Winer A, Thibault L, André H, Tixier F, et al. Serious acute chikungunya virus infection requiring intensive care during the reunion island outbreak in 2005-2006. Crit Care Med. 2008;36(9):2536-41.

42. Kee ACL, Yang S, Tambyah P. Atypical chikungunya virus infections in immunocompromised patients. Emerg Infect Dis. 2010;16: 1038-40.

43. Dalla Gasperina D, Balsamo ML, Garavaglia SD, Rovida F, Baldanti F, Grossi PA. Chikungunya infection in a human immunodeficiency virus-infected kidney transplant recipient returning to Italy from the Dominican Republic. Transpl Infect Dis. 2015;17(6): 876-9.

44. Pierrotti LC, Lopes MIBF, do NAP, Caiaffa-Filho H, Lemos FBC, Reusing JO, et al. Chikungunya in kidney transplant recipients: a series of cases. Int J Infect Dis. 2017;64:96-9.

45.• Girão ES, Rodrigues BG, Santos D, Do Amaral ES, Costa PEG, Pereira KB, et al. Chikungunya infection in solid organ transplant recipients. Transplant Proc. 2017;49(9):2076-81. This study described the largest number of CHIKV infection in solid organ transplant recipients and their particularities.

46.• Burt FJ, Rolph MS, Rulli NE, Mahalingam S, Heise MT. Chikungunya: a re-emerging virus. Lancet. 2012;379(9816):66271. This article provides a current overview of Chikungunya with special attention to the clinical manifestations and pathogenesis.

47. Wang YM, Lu JW, Lin CC, Chin YF, Wu TY, Lin LI, et al. Antiviral activities of niclosamide and nitazoxanide against chikungunya virus entry and transmission. Antivir Res. 2016;135:81-90.

48.• Petersen LR, Jamieson DJ, Powers AM, Honein MA. Zika Virus. N Engl J Med. 2016;374(16):1552-63. This article provides a current overview of Zika Virus.

49. Mac Namara FN. Zika virus: a report on three cases of human infection during an epidemic of jaundice in Nigeria. Trans R Soc Trop Med Hyg. 1954;48(2):139-45.

50. Duffy MR, Chen T-H, Hancock WT, Powers AM, Kool JL, Lanciotti RS, et al. Zika virus outbreak on Yap Island, Federated States of Micronesia. N Engl J Med. 2009;360(24):2536-43.

51. Ioos S, Mallet HP, Leparc Goffart I, Gauthier V, Cardoso T, Herida M. Current Zika virus epidemiology and recent epidemics. Med Mal Infect. 2014;44(7):302-7.

52. Who. Zika Americas. Wkly Epidemiol Rec. 2015;(45):609-16.

53. Shirley D-AT, Nataro JP. Zika virus infection. Pediatr Clin N Am. 2017;64(4):937-51.

54. Jimenez A, Shaz BH, Kessler D, Bloch EM. How do we manage blood donors and recipients after a positive Zika screening result? Transfusion. 2017;57(9):2077-83.

55. Ikejezie J, Shapiro CN, Kim JChiu M, Almiron M, Ugarte C, Espinal MA, et al. Zika virus transmission-region of the Americas, May 15, 2015-December 15, 2016. Am J Transplant. 2017;17:1681-6.

56. Faria NR, Azevedo R, Kraemer MUG, Souza R, Cunha MS, Hill $\mathrm{SC}$, et al. Zika virus in the Americas: early epidemiological and genetic findings. Science. 2016;352(6283):345-9.
57. Salvador FS, Fujita DM. Entry routes for Zika virus in Brazil after 2014 world cup: new possibilities. Travel Med Infect Dis. 2015;2015:1-3.

58. Basile K, Kok J, Dwyer DE. Zika virus: what, where from and where to? Pathology. 2017;49(7):698-706.

59.• Nogueira ML, Estofolete CF, Terzian ACB, Mascarin do Vale EPB, da Silva RCMA, da Silva RF, et al. Zika virus infection and solid organ transplantation: a new challenge. Am J Transplant. 2017;17(3):791-5. Largest Zika case series in solid organ transplantation.

60. Schwartzmann PV, Ramalho LNZ, Neder L, Vilar FC, AyubFerreira SM, Romeiro MF, et al. Zika virus meningoencephalitis in an immunocompromised patient. Mayo Clin Proc. 2017;92(3): 460-6. This article showed that reducing IS because of zika infection led to graft rejection and death.

61. Simkins J, Anjan S, Morillas-Rodriguez JA, Greissman SR, Abbo LM, Camargo JF, Ruiz P, Vianna R, Guerra G, Salama S, Morris MI Screening for Zika virus in deceased organ donors in Florida. Am J Transplant. 2017.

62.• Musso D, Nhan T, Robin E, Roche C, Bierlaire D, Zisou K, et al. Potential for Zika virus transmission through blood transfusion demonstrated during an outbreak in French Polynesia, November 2013 to February 2014. Eurosurveillance. 2014;19(14). First paper to highlight the potential risk of transfusion transmission of ZIKV.

63. Kuehnert MJ, Basavaraju SV, Moseley RR, Pate LL, Galel SA, Williamson PC, et al. Screening of blood donations for Zika virus infection - Puerto Rico, April 3-June 11, 2016. MMWR Morb Mortal Wkly Rep. 2016;65(24):627-8.

64. Slavov SN, Hespanhol MR, Rodrigues ES, Levi JE, Ubiali EMA, Covas DT, et al. Zika virus RNA detection in asymptomatic blood donors during an outbreak in the northeast region of São Paulo state, Brazil, 2016. Transfusion. 2017;57(12):2897-901.

65. Barjas-Castro ML, Angerami RN, Cunha MS, Suzuki A, Nogueira JS, Rocco IM, et al. Probable transfusion-transmitted Zika virus in Brazil. Transfusion. 2016;56(7):1684-8. First report of ZIKV in liver transplant recipient, transmitted by platelet component.

66. Motta IJF, Spencer BR, Cordeiro da Silva SG, Arruda MB, Dobbin JA, Gonzaga YBM, et al. Evidence for transmission of Zika virus by platelet transfusion. N Engl J Med. 2016;375(11):1101-3.

67. US Department of Health and Human Services. Guidance on zika virus. Organ procurement and transplantation Network July 28, 2016. Available from: https://optn.transplant.hrsa.gov/news/ guidance-on-zika-virus/.

68.• Kleber de Oliveira W, Cortez-Escalante J, De Oliveira WTGH, do Carmo, GMI, Henriques CMP, Coelho GE, et al. Increase in reported prevalence of microcephaly in infants born to women living in areas with confirmed zika virus transmission during the first trimester of Pregnancy-Brazil, 2015. MMWR Morb Mortal Wkly Rep. 2016;65(9). First report of increase of microcephaly cases after ZIKV infection in pregnant women.

69. de Paula Freitas B, de Oliveira Dias JR, Prazeres J, Sacramento GA, Ko AI, Maia M, et al. Ocular findings in infants with microcephaly associated with presumed Zika virus congenital infection in Salvador, Brazil. JAMA Ophthalmol. 2016;134(5):529.

70. Rasmussen SA, Jamieson DJ, Honein MA, Petersen LR. Zika virus and birth defects-reviewing the evidence for causality. N Engl J Med. 2016;374(20):1981-7.

71. Raboni SM, Bonfim C, Almeida BM, Zanluca C, Koishi AC, Rodrigues PRVP, et al. Flavivirus cross-reactivity in serological tests and Guillain-Barré syndrome in a hematopoietic stem cell transplant patient: a case report. Transpl Infect Dis. 2017;19(4):1-5.

72. Thiery G, Valentino R, Meddhaoui H. Zika virus-associated Guillain-Barré syndrome: a warning for critical care physicians. Intensive Care Med. 2016;42(9):1485-6. 
73. Siu R, Bukhari W, Todd A, Gunn W, Huang QS, Timmings P. Acute Zika infection with concurrent onset of Guillain-Barré syndrome. Neurology. 2016;87:1623-4.

74. Styczynski J, Hoek J, Knelange N, Mikulska M, Cesaro S, Aljurf $\mathrm{M}$, et al. No report on Zika virus infection in EBMT registry: infectious diseases working party statement. Bone Marrow Transplant. 2017;52(9):1345-6.

75. Silveira FP, Campos SV. The Zika epidemics and transplantation. J Hear Lung Transplant. 2016;35(5):560-3.

76. Shukla S, Hong S-Y, Chung SH, Kim M. Rapid detection strategies for the global threat of Zika virus: current state, new hypotheses, and limitations. Front Microbiol. 2016;7:1685.

77. Mansuy JM, Mengelle C, Pasquier C, Chapuy-regaud S, Delobel P, Martin-blondel G. Zika virus infection and prolonged viremia in whole-blood specimens. Emerg Infect Dis. 2017;23(5):2015-7. The article shows prolonged detection of ZIKV in whole blood and highlights the impact of this finding in donor deferral by blood banks.

78. Gourinat AC, OConnor O, Calvez E, Goarant C, DupontRouzeyrol M. Detection of zika virus in urine. Emerg Infect Dis. 2015;21(1):84-6.

79. Musso D, Roche C, Nhan T-X, Robin E, Teissier A, Cao-Lormeau VM. Detection of Zika virus in saliva. J Clin Virol. 2015;68(1):53-5.

80. Heald-Sargent T, Muller W. Zika virus: a review for pediatricians. Pediatr Ann. 2017;46(11):e428-32.

81. Wichmann O, Vannice K, Asturias EJ, de Albuquerque Luna EJ, Longini I, Lopez AL, et al. Live-attenuated tetravalent dengue vaccines: the needs and challenges of post-licensure evaluation of vaccine safety and effectiveness. Vaccine. 2017;35(42):5535-42.

82. Hadinegoro SR, Arredondo-García JL, Capeding MR, Deseda C, Chotpitayasunondh T, Dietze R, et al. Efficacy and long-term safety of a dengue vaccine in regions of endemic disease. $\mathrm{N}$ Engl $\mathrm{J}$ Med. 2015;373(13):1195-206.

83.• World Health Organization. Dengue vaccine: WHO position paper - July 2016. Vol. 30, Weekly Epidemiological Report. 2016. Available from: http://www.who.int/wer/2016/wer9130.pdf?ua=1. WHO opinion on the limitations of the licensed dengue vaccine and its risks if used in low seroprevalence areas.

84. Magnani DM, Silveira CGT, Ricciardi MJ, Gonzalez-Nieto L, Pedreño-Lopez N, Bailey VK, et al. Potent plasmablast-derived antibodies elicited by the National Institutes of Health Dengue Vaccine. J Virol. 2017;91(22):e00867-17.

85. Barzon L, Palù G. Current views on Zika virus vaccine development. Expert Opin Biol Ther. 2017;17(10):1185-92.

86. U.S. Department of Health and Human Services. Revised recommendations for reducing the risk of Zika virus transmission by blood and blood components. Guidance for industry [Internet]. FDA. 2016. Available from: http:/www.fda.gov/BiologicsBloodVaccines/ Guidance.

87. UNOS. Guidance for organ donation and transplantation professionals regarding the Zika virus [Internet]. 2016. Available from: https://unos.org/guidance-for-organ-donation-and-transplantationprofessionals-regarding-the-zika-virus/. 